\title{
KONSEP METODE DAKWAH BIL HIKMAH \\ DAN IMPLEMENTASINYA DALAM TABLIGH
}

\author{
Nazirman ${ }^{1}$ \\ ${ }^{1}$ UIN Imam Bonjol Padang \\ Email : azirmanma@gmail.com
}

\begin{abstract}
Hikmah salah satu prinsip metode dakwah dalam al-Quran seperti dijelaskan dalam surat an-Nahl ayat 125. Prinsip metode hikmah tersebut memerlukan penyabaran yang bersifat operasional dalam memberikan pemahaman yang tepat kepada para dai untuk merelisasikan prinsip-prinsip dalam berbagai aktivitas dakwah termasuk tabligh.Tabligh salah bentuk dakwah billisan dengan menggunakan kemampuan berbicara atau melisankan materi dakwah kepada umat dengan berbagai teknik yang dipandang bijak dan sesuai dengan kaedah hikmah untuk memahamnkan ajaran Islam sebagaimana seharusnya
\end{abstract}

Keyword : Dakwah, Hikmah, Tabligh

\section{PENDAHULUAN}

Metode merupakan cara dan proses sistematis yang dilakukan oleh seseorang untuk mencapai sesuatu. Metode sangat penting artinya dan tak kalah pentingnya dengan isi, bahkan ada yang mengungkapkan bahwa cara lebih penting dari metode (at-Thariqatu ahammu minal maddah).

Hikmah salah satu prinsip metode dakwah dalam al-Quran seperti dijelaskan dalam surat anNahl ayat 125 . Prinsip metode hikmah tersebut memerlukan penyabaran yang bersifat operasional dalam memberikan pemahaman yang tepat kepada para dai untuk merelisasikan prinsip-prinsip dalam berbagai aktivitas dakwah termasuk tabligh.

Tabligh salah bentuk dakwah billisan dengan menggunakan kemampuan berbicara atau melisankan materi dakwah kepada umat dengan berbagai teknik yang dipandang bijak dan sesuai dengan kaedah hikmah untuk memahamnkan ajaran Islam sebagaimana seharusnya.

Pembahasan tentang dakwah bilhikmah sudah banyak yang membahas. Hanya saja pembahasan tersebut masih memerlukan penyabaran yang bersifat praktis dan operasional, sehingga konsep-konsep dakwah dengan metode hikmah dapat diturunkan menjadi kajian yang praktis dan terapan. Pada akhirnya dengan upaya tersebut diharapkan para dai dapat merealisasikan dakwahnya dengan bijak melalui penerapan metode hikmah yang lebih teknis dan aplikatif.

\section{A. Fokus}

Fokus kajian ini membahas definisi (at-ta'rifat bentuk turunan 
dan penerapannya dalam aktivitas dakwah billisan.

\section{B. Metode Pembahasan}

Kajian ini mengunakan kajian tematik dimana aktivitas pembahsan difokuskan kepada pembahasan tema-tema yang berkaitan dengan hikmah dalam bebagai literatur.

\section{Konsep Dakwah bil hikman}

\section{Pengertian Hikmah}

Hikmah secara harfiah berasal dari bahasa Arab yang akar katanya حكم yang berarti ungkapan yang mengandung kebenaran dan mendalam (Salmadanis, 2003: 122). Dalam keseharian kata hikmah sering kali diterjemahkan dengan bijaksana, yaitu suatu pendekatan yang sedemikian rupa sehingga objek dakwah mampu merealisasikan apa yang didakwahkan dengan kemauannya sendiri, tidak merasa terpaksa ataupun meresa tertekan (Samsul Munir Amin, 2009 : 98). Dalam bahasa komunikasi disebut sebagai Frame of reference, field of reference, dan field of experience, yaitu situasi total yang mempengaruhi sikap pihak komunikan (objek dakwah) (Toto Tasmara, 2001:37).

Pengertian hikmah secara istilah dikemukan oleh para ulama mempunyai makna yang beragam seperti :

1. Hikmah merupakan kenabian

2. Hikmah adalah al-Qur'an dan pemahaman terhadapnya

3. Hikmah adalah tepat dalam perkataan dan perbuatan

4. Hikmah adalah wara' (menjauhkan diri dari perbuatan ma'

5. Hikmah adalah ilmu yang bermanfaat, ilmu amaliyah dan aktivitas yang membawa kepada kemashlahatan umat
6. Hikmah merupakan sunnah Nabi

7. Mengetahui kebenaran dan beramal dengannya, berpengetahuan yang luas dalam pembicaraan dan amal dengan berpegang teguh kepada al-Qur'an dan alSunnah

8. Hikmah merupakan kondisi psikologis seperti ketundukan, kepasrahan, dan ketakutan kepada Allah.

9. Hikmah adalah meletakan sesuatu pada tempatnya yang benar pengetahuan al-da'i terhadap objek dakwah dan memilih metode serat media yang relevan dengan mereka (Said Bin Ali Al-Qahthani, 1994 :22-23).

Dari pengertian-pengertian di atas dapat dikemukan bahwa seorang da'i yang bijak-mampu menerapkan konsep hikmah dalam makna memiliki bekal ilmu yang mendalam tentang aldin al-Islamy dengan memahami alQur'an dan al-Sunnah sebagai dasarnya, mempunyai ilmu tentang psikologi yang akan menuntun juru dakwah bersikap bijaksana dalam menyampaikan dakwah, bersikap proporsional dan professional dalam memilih materi dan metode serta teknik penyampaian dakwah sesuai dengan level objek dakwah.

Al-hikmah juga menuntut persiapan spiritual seorang da'i, ketundukan, kepasrahan, ketakutan kepada Allah serta sifat wara' menjadi control utama da'i dalam berdakwah. Karena sisi spritual inilah yang mampu menjadikan da'i istiqamah, benar dan terkontrol dalam dakwahnya.

Said Quthb mengemukakan bahwa dakwah dengan metode hikmah akan terwujud apabila memperhatikan tiga faktor:

1) Keadaan dan situasi orang yang akan didakwahi 
2) Kadar atau ukuran materi dakwah yang akan disampaikan agar mereka merasa tidak keberatan dengan beban materi tersebut.

3) Metode penyampaian materi dakwah dengan memuat variasi sedemikian rupa yang sesuai dengan kondisi pada saat itu (Asep Muhyiddin, 2002:80).

\section{LANDASAN DAKWAH BIL HIKMAH}

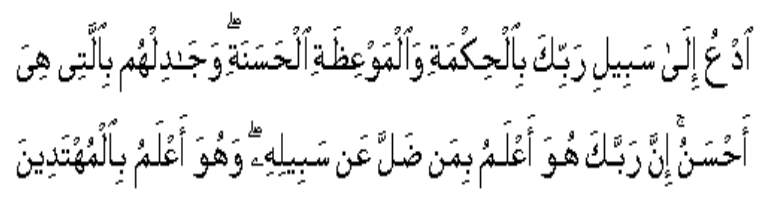

Artinya: Serulah (manusia) kepada jalan Tuhan-mu dengan hikmah dan pelajaran yang baik dan bantahlah mereka dengan cara yang baik. Sesungguhnya Tuhanmu dialah yang lebih mengetahui tentang siapa yang tersesat dari jalan-Nya dan dialah yang lebih mengetahui orang-orang yang mendapat petunjuk.(Qs. An-Nahl :125)

Said Quthb mentafsirkan ayat-ayat ini dengan menguraikan sebagai berikut:

- Berdakwahlah ke jalan Allah bukan untuk pribadi juru dakwah dan bukan pula untuk kaum atau golongannya. Bagi juru dakwah tidak ada kepentingan apa-apa dari dakwahnya itu, kecuali hanya menunaikan kewajibannya karena Allah; dia tidak mendapatkan kelebihan apa-apa dari pembicaraannya, juga tidak boleh mengharap apa-apa dari orang yang didakwahkannya kecuali dia mendapat pahala dari Allah.

- Berdakwalah dengan hikmah, memperhatikan keadaan orang yang didakwahi dan lingkungannya, dengan menggariskan tingkat pelajaran yang akan dijelaskan kepada mereka tiap-tiap kalinya, sehingga tidak memberatkan dengan tugas yang banyak sebelum cukup persiapan mental mereka untuk itu; dengan memperhatikan system dakwah yang dipergunakannya serta menyesuaikan dengan kebutuhan, sehingga jangan sampai terlalu menonjol semangat, pembelaan dan gairah yang melampau hikmah (A. Hasjmy, 1994:55).

Dengan demikian hikmah dalam berdakwah dimulai dari tahap persiapan internal berupa ruhiyah, fikriyah dan jasadiyah dan persiapan eksternal berupa metode dan strategi dakwah dan keadaan objek dakwah. Kemudian diikuti dengan anjuran berdakwah dengan mau'izhah hasanah yaitu berupa sarana komunikasi berupa pelajaran yang indah yang masuk ke dalam hati dan menyentuh perasaan. Setelah itu apabila diperlukan untuk berdebat maka berdebat dengan cara lebih santun.

\section{SENDI SENDI DAKWAH BIL HIKMAH}

Untuk bijak dalam berdakwah diperlukan sendi-sendi dakwah meliputi : ilmu, sabar dan tidak tergesa-gesa (Said bin Ali Al-Qahthani, 1994:32).

a. Ilmu

Ilmu merupakan sendi terpenting dari hikmah, sesuai dengan firman Allah dalam Surat Muhammad ayat 19:

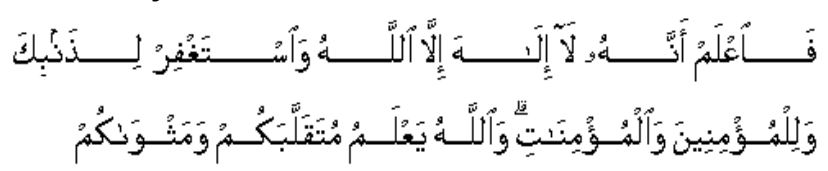


Artinya: Maka Ketahuilah, bahwa Sesungguhnya tidak ada Ilah (sesembahan, Tuhan) selain Allah dan mohonlah ampunan bagi dosamu dan bagi (dosa) orangorang mukmin, laki-laki dan perempuan. dan Allah mengetahui tempat kamu berusaha dan tempat kamu tinggal.

Ayat ini memberikan signal bahwa ilmu merupakan hal pertama yang diprioritaskan, dan ilmu yang lebih utama ialah berilmu dengan Allah sebagai Ilah yang disembah. Kemudian amal saleh dan memohon ampun untuk diri dan orang lain. Memohon ampun merupakan aktivitas amal yang ditimbulkan dari inzar yang dilakukan dalam aktivitas dakwah/ al-amru bil ma'ruf dan nahyu 'anil munkar. Kemudian agar bijak seorang dai juga memahami berbagai disiplin ilmu pendukung untuk menghadapi dan memenuhi benutuhan umat yang didakwahinya.

b. Sabar (hilm)

Al-hilm berarti akal atau dewasa. Orang halim berarti berhati-hati dan tenang ketika marah atau tidak membalas sekalipun dia mampu melakukannya.

Sendi hilm ini sangat penting dalam dakwah bil hikmah, karena dengan kesabaran yang tinggi seorang mampu menghadapi objek dakwah yang beragam karakter dan tingkat pendidikannya. Kesabaran ini juga sering dikaitkan dengan ilmu, karena dengan ilmu seorang da'i mampu menghadapi objek dakwah dengan penuh santun dan sabar. Pengetahuan terhadap psikologi sosial masyarakat dapat membantu da'i bersikap sabar dalam menghadapi keberagaman karakter objek dakwahnya.

Dalam ayat berikut Allah menggandeng sifat sabar/ santun dengan Maha Mengetahui ('alim):

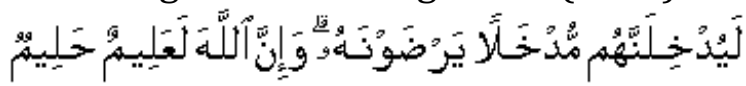

Artinya: Sesungguhnya Allah akan memasukkan mereka ke dalam suatu tempat (syurga) yang mereka menyukainya. dan Sesungguhnya Allah Maha mengetahui lagi Maha Penyantun (Al Hajj : 59).

c. Tidak tergesa-gesa (al-Anaah)

Al-anaah ialah melangkah pasti dengan tidak tergesa-gesa/ berhati-hati. Sifat al-anaah ini perlu dimiliki oleh setiap da'i dalam menyampaikan dakwah dengan terus berhati-hati dalam berkata dan bersikap. Sikap hatihati dan tidak tergesa-gesa ini merupakan implikasi dari kedalaman ilmu seorang da'i yang bisa melihat situasi dan kondisi objek dakwah kemudian berfikir secara professional dan proporsional menerapkan metode yang sesuai untuk setiap level objek dakwah.

\section{PENERAPAN METODE HIKMAH KEPADA UMAT}

Berdakwah dengan hikmah telah dicontohkan oleh Rasulullah, sahabat dan tabi'in. metode ini merupakan strategi penting dalam keberhasilan dakwah Islam sepanjang sejarah.

a. Aplikasi hikmah dalam dakwah Rasulullah SAW

Sikap bijak nabi SAW meliputi sendi-sendi hikmah, di antaranya bersikap sabar menghadapi objek dakwah. Sikap ini selalu dikedepankan Nabi dalam berdakwah sehingga 
meluluhkan kekerasan hati orangorang yang membangkang. Pada saat Nabi hijrah ke Thaif, beliau mendapat perlakuan yang semena-mena dari masyarakat Thaif sehingga malaikat Jibal (gunung) dan malaikat Jibril yang diutus oleh Allah untuk menemani Nabi menawarkan diri untuk diperintah untuk menghancurkan mereka. Dari Aisyah R.A menceritakan jawaban rasulullah ketika mendengar tawaran malaikat Jibal "Aku mengharap Allah mengeluarkan dari tulang rusuk mereka orang-orang yang menyembah Allah dan tidak syirik kepada-Nya. (HR. Bukhari dan Muslim) (Said bin Ali Al-Qahthani, 1994:119).

Sikap bijak Nabi dalam kasus ini dapat dilihat dari kesabaran yang luar biasa menghadapi objek dakwah yang membangkang. Nabi SAW membalas perbuatan jahat mereka dengan doa yang tulus untuk kebaikan mereka di masa mendatang.

Dalam kesempatan lain, Nabi bersikap bijak terhadap seorang pemuda yang meminta izin untuk berzina. Dari Abi Umamah diceritakan "Seorang pemuda datang kepada Nabi dan berkata: wahai Rasulullah, izinkan aku berzina! Jamaah yang hadir spontan menghardiknya, "hei, pergilah kamu, tinggalkan tempat ini!" namun Nabi SAW berkata sebaliknya, 'mendekatlah kamu ke sini! Lalu dia mendekat. Nabi bertanya kepadanya 'apakah kamu senang apabila ibumu dizinahi orang? Demi Allah, tentu tidak, jawabnya. 'begitu juga orang lain tidak senang jika ibunya dizinahi' kata Nabi seraya bertanya lagi 'apakah akamu senang anak gadismu dizinahi orang? 'demi Allah tentu tidak ya Rasul' jawab pemuda itu. 'begitu juga orang lain tidak senang anak jika gadisnya dizinahi orang. Kata Nabi 'apakah kamu senang jika saudara perempuanmu dizinahi orang? 'tentu tidak ya rasul' jawabnya. 'begitu juga orang lain tidak senang jika saudara perempuannya dizinahi', kata Nabi. 'Apakah kamu senang jika bibimu dizinahi orang? 'tentu tidak ya Rasul' jawab pemuda itu. 'begitu juga orang lain tidak senang jika bibinya dizinahi. Kata Nabi ' apakah kamu senang jika saudari ayahmu dizinahi? 'tentu tidak ya Rasulullah' jawabnya. Begitu juga orang lain tidak senang jika saudari ayahnya dizinahi' kata Nabi untuk kesekian kalinya. Lalu Nabi meletakkan tangannya ke atas pundak pemuda itu, sambil berdoa, Ya Allah Ampunilah dosanya, sucikanlah hatinya dan peliharalah kemaluannya. Sejak itu pemuda tersebut tidak berkeinginan lagi berzina. (H.R Ahmad) (Said bin Ali Al-Qahthani, 1994:148).

Dari dua contoh di atas dapat dipahami bahwa bijaknya Rasulullah menghadapi objek dakwahnya, sikap bijak yang dilandasi dengan ilmu dan kesabaran serta kehati-hatian.

b. Aplikasi hikmah dalam dakwah sahabat

Sikap bijak Abu Bakar R.A setelah Nabi wafat : Saat wafatnya Nabi adalah saat kesedihan terperih bagi umat Islam bahkan rasa tak percaya merundung hati mereka. Setelah Abu Bakar memastikan bahwa Rasulullah benar-benar telah meninggal. Abu Bakar keluar menemui orangorang dan berkata: "Barangsiapa yang menyembah Muhammad, maka sesungguhnya Muhammad telah meninggal dunia, tetapi 
barangsiapa yang menyembah Allah, maka sesungguhnya Allah Maha Hidup dan tidak akan meninggal" (Shafiyurrahman AlMubarakfuri, 2000:620). Sikap bijak yang dilandasi dengan ketegasan dan kehati-hatian telah Abu Bakar tunjukkan dalam peristiwa ini. Berkata benar walaupun pahit menggunakan bahasa yang tegas dan menyentuh nurani.

c. Aplikasi hikmah dakwah tabi'in Sikap bijak Imam Abu hanifah ketika menghadapi orang atheis dan mengajaknya untuk beriman kepada Allah SWT. Dikisahkan bahwa sekelompok orang atheis bertemu dengan Imam Abu Hanifah dalam sebuah forum dialog:

Kaum Atheis : "Apakah buktinya tentang adanya pencipta?"

Abu Hanifah : "aku sedang memikirkan sesuatu kejadian yang aneh"

Kaum Atheis : "Apa itu?"

Abu Hanifah : "Aku telah mendengar

bahwasanya di

Dajlah terdapat sebuah kapal besar yang sarat dengan penumpang dan barang-barang, tetapi anehnya kapal itu berlayar tanpa nahkoda."

Kaum Atheis : "Apakah kamu gila, Abu Hanifah? Kapal macam apa yang kamu ceritakan itu, sungguh tidak masuk akal dan tidak bisa diterima akal sehat."
Abu Hanifah : "Kalau itu suatu yang mustahil, sekarang

bagaimana kalian bisa menyakini bahwa alam dan seisinya serta kejadian-

kejadiannya-

seperti bintang yang bergerak pada orbitnyaada yang membuat dan menggerakkan?

Mengapa kalian tidak percaya adanya pencipta yang menggerakkan semua itu?

Mendengar jawaban sekaligus pertanyaan balik Abu Hanifah, mereka terdiam (Said bin Ali Al-Qahthani, 1994:199).

Dalam konteks ini $\mathrm{Abu}$ Hanifah telah mencontohkan sikap bijak yang berdasarkan ilmu dan kehati-hatian, tidak mendikte objek dakwahnya, tetapi memberikan kesempatan kepada mereka untuk berfikir dengan potensi logika yang mereka miliki. Dalam peristiwa ini tampak kepiawaian Abu Hanifah melihat type objek dakwahnya yang membangkang dari kebenaran berdasarkan logika, maka Abu Hanifah juga mendakwahi mereka dengan mengadu logika.

\section{KONSEP PENERAPAN HIKMAH DALAM TABLIGH}

Tabligh diamakani dengan proses mempersentasikan, menyampaikan pesan-pesan dakwah dengan mengunakan lisan. Lisan dikaitkan dengan kemampuan menggunakan bahsa atau berbicara dihadapan publik. 
Jika dikaitkan dengan himah berbaicara adalah memngunkan kata-kata dalam menjaikan pesanpesan dakwah-bertabligh dengan kata-kata yang bijak.

Penerapan Metode Hikmah dalam berbicara atau dakwah billisan terakomudir dalam bentuk diksi dan komposisi bahasa yang diuturkan atau digunakan dengan cara-cara yang penuh kearifan.

Penggunaan kata-kata dan sistem penyajiannya dapat diterapkan melalui metode komperatif (muqarran), berkisah, dan pemberian contoh (amsal). Sikap bijak seoarang dai dalam menerapkan metode hikmah ini direalisir dalam penetuan sikap kapan saatnya berbicara dan kapan sebaiknya mengambil posisi diam serta sangat berhati-hati menggunakan kata yang disesuaikan dengan kebutuhan, kesanggupan dan daya serap para penerima pesan dakwah. Hal ini dimulai dari berbagai pertimbangan yang matang terhadap ketepatan, kegunaan dan kecermatan dalam berbicara.

Pertimbangan yang matang dalam memilih kata dan cara berdakwah dalam konteks dakwah bijak dapat ditemukan dalam Fiqih muwazanat antara lain ialah sebagai berikut:

- Pertimbangan antara beberapa kemaslahatan yang satu dengan yang lainnya ditinjau dari segi kadar dan kapasitasnya, kedalaman dan pengaruhnya, keabadian dan kesinambungannya.

- Pertimbangan antara beberapa kerugian yang satu dengan yang lainnya ditinjau dari berbagai sudut pandang di atas. Kerugian mana yang harus didahulukan antisipasinya dan mana pula yang harus ditunda atau digagalkan.

- Pertimbangan antara kemaslahatan dan kerugian
(Yusuf Qardhawy, 1993:2728).

Firman Allah dalam surat alKahfi ayat 79

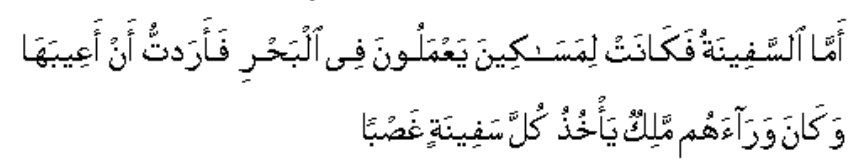

$$
\begin{aligned}
& \text { Artinya:Adapun bahtera itu } \\
& \text { adalah kepunyaan } \\
& \text { orang-orang miskin } \\
& \text { yang bekerja di laut, } \\
& \text { dan Aku bertujuan } \\
& \text { merusakkan bahtera } \\
& \text { itu, Karena di hadapan } \\
& \text { mereka ada seorang } \\
& \text { raja yang merampas } \\
& \text { tiap-tiap bahtera. }
\end{aligned}
$$

Dalam ayat ini, pertimbangannya adalah perahu itu tetap ada di tangan pemiliknya (meskipun telah bocor) daripada hilang sama sekali (dirampas oleh seorang raja). Pertimbangan dan prioritas inilah yang akan menuntun para da'i untuk dapat bersikap hikmah dalam berdakwah.

Secara teknis penerapan meto hikmah pada aspek muqaran, amsal, dan aqsam dengan spesifikasi sebagai :

\section{Komparatif (muqarran)}

Kata Qarana, yuqarinu, قارن، (قان ) قارن، ( ) muqaran ( ( مقارن adalah isim masdhar dari qarana ( قارن), berarti menghubungkan, mengumpulkan dan memperbandingkan, atau membedakan dua sesuatu dengan sesuatu yang lainnya(Ibrahim Musthafa, 1989:730). Dalam bahasa Inggris disebut (comparative) yang berarti perbandingan (J.Milton Cowan, $1971:$ 760).

\section{Proses}

Perbadingan dilakukan secara sederjat dan seimbang terhadap satu pokok pembahasan atau yang dikaji dan disajikan Misalnya membandikan cara suatu komunitas dalam 
perilaku hidup bersih dikomperatifkan dengan perilaku komuitas lain yang berperilaku hidup bersih.

Berkaitan dengan muqarran dalam al-Qur'an ditemukan kalimat pertanyaan dengan memakai huruf istifham (harrazgh) (Badr al-Din Muhammad Bin Abd Allah alZarkasyi, 1990: 348). seperti surat al-Qalam ayat 35 (68/02) yaitu; (35 أفنجعل المسلمين كا ( لمجر مين

Contoh perbadingan dalam al-Qur'an dicontohkan dengan orang yang mendapat cahaya (نورا) dan orang yang masih berada pada kegelapan (الظلمات ) sebagaimana terdapat dalam surat al-An'am ayat 122 ( 06/55), antara musyrik dengan 'abid, serta orang yang mengetahui dengan orang yang tidak mengetahui, sebagaimana tercermin dalam surat al-Zumar ayat 9 (39/59), selanjutnya alQur'an meyebutkan perbedaan antara orang yang celaka dan orang-orang yang sentosa di akhirat kelak, al-Qur'an surat Fushshilat ayat 40 (41/61).

\section{Kisah}

Kata kisah diambil dari akar bahasa Arab; قص، يقص، قصا L(qashsha, yaqushshu, qashsha, shan), berarti menceritakan kabar kepadanya, atau bermakna pokok menunjukkan untuk mengikuti sesuatu yang dikisahkan. (al Husein Ahamd bin Faris bin Zakaria, 1969: 11) Berkisah juga berarti menceritakan sesuatu. Sedangkan dalam bahasa Indonesia qashash menjadi kisah diartikan dengan cerita tentang kejadian (riwayat) kehidupan seseorang.

Kisah dalam KBBI diterjemahkan dengan cerita, kejadian (riwayat) sejarah dan sebagainya. Cerita adalah tuturan yang membentangkan bagaimana terjadinya suatu hal (peristiwa), kejadian dan sebagainya). Sejarah adalah kejadian dan peristiwa yang benar-benar terjadi pada masa lampau.

Kisah di dalam al-Qur'an ditemukan beragam (shighat) yang berakar dari qasha, yaqashu dan qishashan berjumlah 30 kali dalam berbagai surat dan ayat (Muhammad Fuad Abdu al-Baqi, 1992:693). Kisah yang tidak diambil dari kata-kata qashsa atau qishasan atau ayat-ayat yang memuat cerita tentang sesuatu ditemukan dalam al-Qur'an sebanyak 15 kali. Makkiyah 11 surah dan Madaniyah 4 surah.

Jika dicermati ayat-ayat yang berkoleasi dan meiliki relevansi dengan kisah, maka ditemukan dan dapat dikemukan bahwa bahwa alQur'an mengungkapkan tentang :1). Peristiwa-peristiwa sejarah yang terjadi dengan menyebutkan pelakupelaku dan tempat terjadinya. 2). Peristiwa yang telah terjadi dan masih dapat terulang kejadiannya, 3). Peristiwa simbolis yang tidak menggambarkan suatu peristiwa yang telah terjadi namun dapat saja terjadi sewaktu-waktu.

Kisah dalam bertabligh sebagaiman dikemukan oleh Hasbi Ash-Shiddiqi bahwa kisah memberi faedah terutama dalam menjelaskan Islam kepada masyarakat, meliputi;

1) Pengajaran yang tinggi yang menjadi cermin perbandingan bagi segala ummat. Di dalamnya kita dapati akibat kesabaran. Sebagaimana sebaliknya kita dapati akibat keingkaran.

2) Mengokohkan Muhammad, membuktikan kebenarannya. Muhammad adalah seorang ummy dan yang hidup dalam masyarakat yang ummy. Maka bagaimana ia dapat meriwayatkan sejarah-sejarah 
yang penting kalau bukan yang demikian itu dari wahyu.

3) Memberi petunjuk kepada penyeru, jalan jalan yang harus mereka turuti dalam melaksanakan seruan dalam menghadapi kaum-kaum yang ingkar.

4) Menerangkan betapa kesungguhan dan ketelitian ulul 'azmi dalam memberikan petunjuk kepada manusia (T.M. Hasbi Ash-Shiddiqy, 1980:160).

Manna Khalil al-Qattan juga menegaskan bahwa kisah merupakan metode yang digunakan bagi juru dakwah dan pendidik. Karena mereka tertarik mendengar atau membaca suatu kisah yang tanpa disadarinya mereka telah menerima pesan berupa nasehat, petunjuk, pengajaran dan sebagainya dari kisah tersebut. Terutama dapat membekali audiensnya tentang peri kehidupan Nabi, beritaberita tentang umat dahulu (Manna Khalil al-Qattan, 1981:436).

Bagi mubaligh berkisah menjadi metode penyajian yang menarik dan digemari oleh banyak orang dan akan menebus relung jiwa manusia dengan mudah. Karena sifat dasar manusia juga senag bercerita dan mendengarkan cerita. (Hasil riset tentang kisah).

\section{Amsal}

Amsal diambil dari akar kata masal, misal dan masil dan dalam bentuk isim, al-matsilu, almitslu dan bentuk jama'nya amsal (Ibrahim Mustafa, 1995: 853) sama dengan syabah, syibh dan syabih. Kata amsal dalam bahasa Indonesia dapat berarti perumpamaan atau bandingan.
Al-Isfahani, mengungkapkan bahwa masal disebut misl (perumpamaan), seperti dalam alQur'an منل الجنة التى و عد المتقون juga berarti musyabbih (menyerupai) contoh dalam al-Qur'an ليس كمناه ثئ. Amasal adalah suatu ungkapan yang menggambarkan sesuatu yang lain, yang ada di dalamnya titik persamaan (Al-Raghib al-Isfahani,482).

Kata masal yang bermakna keadaan ditemukan dalam al-Qur'an surat Muhammad; 15. amsal yang bermakna menampakkan sesuatu makna yang absrak dalam bentuk yang inderawi (mahsus)bertujuan agar menjadi indah dan menarik serta mempunyai pengaruh mendalam terhadap jiwa (Ahmad Jamal al-Umari, 1982: 3). Manna alQatan dalam hal ini mengartikan dalam bentuk yang indah dan simpel yang mempunyai pengaruh yang mendalam terhadap jiwa, baik berupa tasybih maupun dalam bentuk ungkapan bebas (mursal).

Dengan demikian amsal merupakan ungkapan yang berbentuk persamaan (analogi) atau penggambaran yang terdapat dalam al-Qur'an dengan gaya bahasa yang indah dan menarik dengan tujuan untuk memudahkan memahami dan meresapi tujuan dari kandungan alQur'an.

Jika dikaitkan dengan tablih, maka penerapan teknik amsal ditandai dengan seberapa banayak mubaligh memberikan analogi, perumpaan terhadap sesuatu untuk memeprkuat dan mempermudah umat menerima dan meyakini ajaran yang dibalighkan.

Jika ditinjau dari segi keutamaan dan kegunaan metode amsal dalam bertabligh, maka dapat dijelaskan sebagai berikut:

1) Perumpamaan yang absrak dengan bentuk kongkrit, sehingga dapat ditangkap oleh 
indera, seperti Firman Allah surat al-Baqarah; 264

2) Memberi dorongan untuk berbuat kebajikan, seperti firman-Nya surat al-Baqarah;261

3) Menjauhkan dari perbuatan yang keji, seperti firman-Nya surat alHujurat; 12

4) Mengungkapkan hal yang ghaib dalam bentuk yang hadir, seperti pemakan riba yang tidak tenteram jiwanya, bagaikan orang yang kemasukan setan.

5) Memberikan pujian, seperti pujian Allah kepada Nabi clan orang-orang mukmin, yaitu seperti tanaman yang mengeluarkan tunas, dengan tunas itu tanaman menjadi kuat, besar dan tegak dengan lurus, sehingga membuat orang-orang kafir menjadi jengkel atas kekuatan orang mukmin. Hal ini tergambar dalam firman-Nya surat al-Fath; 29

\section{Aqsam (Sumpah)}

Aqsam bentuk jama' (plural) dari akar kata qasama yang berarti al-hilf atau al yamin, yaitu sumpah. Atau tidak meletakkan pada sesuatu selain pada posisinya (Al-Raghib alIsfahani,418) Bentuk kata aqsam dalam al-Quran diganakan dalam berbagai versi seperti Al-hilf digunakan untuk celaan terhadap orang-orang kafir (munafik) yang melanggar sumpah dan hanya satu ayat yang ditujukan untuk orang mukmin yang membatalkan sumpah dengan membayar kufarat (almaidah, 5:89) Sedangkan qasam pada umumnya digunakan untuk sumpah yang benar (Aisyah Abdurrahman, 1996: 279). Al yamin yang secara harfiyah diartikan dengan tangan kanan, digunakan dalam makna sumpah karena sudah menjadi tradisi orang Arab apabila bersumpah kedua tangan kanannya saling berjabatan (Said Bin Ali Al-
Qahthani, 1994 :291). Di dalam alQur'an aqsam atau ungkapan yang semakna dengannya ditemukan sebanyak 86 kali.

Penerapan aqsam (sumpah) dalam tabligh yang merupakan bagian dari dakwah billisan adalah untuk memberi isyarat kepada mubaligh agar menyesuaikan ushlub bahasa yang dipakai untuk masyarakat tertentu yang dalam ilmu ma'ani disebut adrubul khabar alsalasah atau tiga macam pola pengunaan kalimat berita, yaitu-: ibtida', talabi dan inkari.

Ibtida $i$ dimaksudkan adalah menguatkan pernyataan-meyakinkan pendegar yang berhati kosong dan tidak memiliki persepsi dan pengetahuan terhap peryataan hukum yang disampaikan kepadanya.

Talabi diartikan dengan menyampaikan pernyataan qasam dalam rangka menghilangkan keraguraguan tentang kebenaran sesuatu.

Ikari adalah qasam yang ditujukan kepada orang-orang yang menginkari kebenaran yang disampaikan dengan cara memberikan penguatan sesuai dengan kadar keengkarannya.

Manna

al-Qatthan

menegaskan bahwa qasam bertujuan untuk menghilangkan keraguan, menguatkan khabar celaan, melenyapkan kesalah pahaman terhadap sesuatu sebelumnya, dan untuk menegakkan argumentasi dengan cara yang paling sempurna (Said Bin Ali Al-Qahthani, 1994 :291).

Qasam dalam kaitannya dengan tabligh, berfungsi sebagai penguat perkataan untuk memantapkan hati para audiens dan memperkuat kebenaran di dalam jiwanya. 


\section{KESIMPULAN}

Dari penjelasan di atas dapat disimpulkan bahwa hikmah merupakan prinsip metode dakwah dalam al-Quran yang digunakan dalam berbagai bentuk dakwah termasuk dakwah billisan. Dakwah billisan disebut juga dengan tabligh

Penerapan tutunan dari prisip hikmah dalam tabligh diimplementasikan dalam bentuk muqaran, amsal, kisah dan qasam. Aqsam. Ketiga aspek ini bertujuan untuk meyakinkan, menguatkan dan menghilangkan keragu-raguan terhadap isi dan pesan tabligh yang disampaikan oleh para mubaligh.

\section{DAFTAR KEPUSTAKAAN}

Abdul Khaliq, Abdurrahman, Methode dan Strategi Dakwah Islam pent. Marsuni Sasaky, (Jakarta:Pustaka Al-Kautsar), 1996.

Ali Al-Qahthani, Said, Dakwah Islam Dakwah Bijak, penterjemah Masykur hakim, Jakarta: Gema Insani Press, 1994,

Hasjmy, A., Dustur Dakwah Menurut AlQur'an, Jakarta:Bulan Bintang, 1994.

Juwaini, Ahmad, Gerakan Dakwah Islam 2000, Bandung: Pustaka Misykat, 1997.

Al-Mubarakfuri, Shafiyurrahman, Sirah Nabawiyah, Jakarta:Pustaka Alkautsar, 2000.

Muhyiddin, Asep dan Agus Ahmad Syafei, Metode Pengembangan Dakwah, Bandung:Pustaka Setia,2002.

Natsir, M. Fiqhud Dakwah, Surakarta: Yayasan kesejahteraan Pemuda Islam, 1981

Salmadanis, Filsafat Dakwah, Jakarta:Surau, 2003.
Dakwah dalam Perspektif AlQur'an, Jakarta: The Minangkabau foundation, 2002

Qardhawy, Yusuf, Prioritas Gerakan Islam, pent. A, Najiyullah, Jakarta;AlIshlahy Press, 1993.

Quthb, Said, Fiqih Dakwah, Jakarta: Pustaka Amani, 1995 